DOI 10.37882/2500-3682.2021.02.19

\title{
БОС-ТРЕНИНГ В РЕАБИЛИТАЦИИ ПАЦИЕНТОВ, ПЕРЕНЕСШИХ АОРТОКОРОНАРНОЕ ШУНТИРОВАНИЕ
}

\section{BOS-TRAINING IN REHABILITATION OF PATIENTS UNDER AORTICORONARY BYPASSING}

\section{E. Minko}

Summary: This article presents the results of a feedback experiment at the second stationary stage of complex rehabilitation of patients after coronary artery bypass grafting. At the pilot stage of the study, it was shown that patients who underwent biofeedback training showed significantly significant improvements in HRV, which were more pronounced compared to the improvements in the control group.

Keywords: biofeedback, heart rate variability, comprehensive rehabilitation, coronary artery bypass grafting, psychophysiological training.
Минко Эльза Анатольевна

Медицинский психолог, ГБУз «Республиканский кардиологический чентр» (Уфра); Аспирант, Башкирский государственный педагогический университет

им. М. Акмуллы (Уфа) elzaminko@mail.ru

Аннотация: В статье представлены результаты исследования с использованием метода биологической обратной связи на втором стационарном этапе комплексной реабилитации больных, перенесших аортокоронарное шунтирование. На пилотном этапе исследования было выявлено, что у пациентов, прошедших обучение психофизиологической релаксации с помощью данного метода, наблюдались достоверно значимые улучшения показателей вариабельности ритма сердца (цена адаптации, индекс вегетативного равновесия, индекс напряжения регуляторных систем организма), которые были более выражены по сравнению с улучшениями в контрольной группе (не проходившей тренинг).

Ключевые слова: биологическая обратная связь, вариабельность сердечного ритма, комплексная реабилитация, аортокоронарное шунтирование, психофизиологический тренинг.

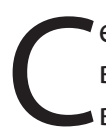
ердечно-сосудистые заболевания (СС3) входят в число наиболее распространенных, выступая, вместе с тем, основной причиной смертности и инвалидизации во многих развитых странах мира, включая Российскую Федерацию [5,6,10,11,12,22].

На сегодняшний день проблема лечения ишемической болезни сердца (ИБС) является одной из наиболее актуальных для мирового и отечественного здравоохранения $[1,5,6,11]$. При этом следует отметить, что случаи летальности, обусловленные ИБС, составляют около половины от общего количества смертей по причине кардиоваскулярных патологий $[5,6,10,12]$. Вышеизложенные данные говорят в пользу актуальности исследования различных аспектов лечения ИБС.

Сегодня одним из наиболее эффективных методов данного заболевания оказывается аортокоронарное шунтирование (АКШ) [3, 21, 24].

В связи с этим в настоящее время в области восстановительной медицины одним из ведущих направлений выступает реабилитация пациентов с сердечно-сосудистыми заболеваниями. При этом медицинская реабилитация (МР) представляет собой важнейший компонент медицинской помощи больным, перенесшим АКШ в качестве реваскуляризации миокарда $[2,7,10,13]$.

В соответствии с современными стандартами ока- зания медицинской помощи, подавляющему числу пациентов, перенесшим острое коронарное событие или кардиохирургическую операцию, следует пройти программу поэтапной реабилитации. Важно отметить, что от успеха МР во многом зависит перспектива благоприятного прогноза вследствие АКШ, поскольку это оказывает существенное влияние на качество жизни пациента, перенесшего операцию, его физическое состояние и психосоциальное функционирование. Вместе с тем, благополучные итоги реабилитации предотвращают необходимость в повторной реваскуляризации миокарда и риск послеоперационной смерти [11,13,23].

В связи с вышесказанным представляются крайне актуальными поиск и внедрение новых методов, позволяющих оптимизировать различные показатели сердечнососудистой системы [4,5, 9,14,16].

В последние годы в России наблюдается всевозрастающая тенденция к использованию альтернативных ортодоксальной медицине безлекарственных методов лечения, в частности, с применением современных информационных технологий $[4,9,14,16]$.

Одним из таких методов, демонстрирующим перспективность применения как в клинической, так и в неклинической сферах, является функциональное биоуправление с биологической обратной связью (БОС), первостепенной задачей которого выступает обучение 
пациента навыкам саморегуляции.

Метод БОС позволяет отражать в параметрах звуковых или световых сигналов обратной связи текущую амплитуду того или иного физиологического показателя человека (биотоков мозга, мышц, сердца, кожи и т.п.). Имеющиеся сигналы предъявляются пациенту, что способствует его обучению сознательно контролировать активности данной функциональной системы организма для достижения требуемых лечебных эффектов.

По существу, метод БОС является нефармакологическим методом лечения и реабилитации $[19,20]$.

С целью усовершенствовать, оптимизировать процесс комплексной реабилитации на втором стационарном этапе комплексной реабилитации пациентов после аортокоронарного шунтирования (АКШ) был внедрен метод биологической обратной связи (БОС) по вариабельности ритма сердца (ВРС). Как следствие, осуществлена оценка показателей ВРС пациентов, перенесших АКШ, в начале и в конце комплексной реабилитации с применением БОС-технологий и без него.

\section{Организашия и методы исследования}

В исследовании на пилотном этапе приняли участие 29 пациентов кардиологического отделения медицинской реабилитации ГБУЗ РКЦ. Средний возраст больных составил 67 лет. Из 29 пациентов 15 были мужчины, 14 - женщины.

В экспериментальной группе (14 испытуемых) для улучшения показателей ВРС применялись технологии психофизиологического расслабления: БОС-тренинги проводились на аппаратном комплексе «ВедаПульс Professional», дополненном диагностическим программным модулем «Академический модуль» и программным модулем реабилитации «Медитация (биоуправление)».

В целях обучения психофизиологическому расслаблению пациентам предлагалось пройти 10 сеансов кардиобиоуправления по 15 минут в течение двух недель и два мониторинга (измерение 1 и 2) в начале и в конце реабилитации (при положенном во время записи количестве интервалов 512).

\section{Результаты исследования и их обсулкение}

В результате комплексной реабилитации с использованием метода биологической обратной связи в экспериментальной группе были получены данные, представленные ниже (таблица 1).

Представленные данные свидетельствуют об улучшении диагностируемых показателей ВРС: АМо (цена адаптации) - на 27,6\%, ИВР (индекс вегетативного равновесия) - на 55,1 \%, ИН (индекс напряжения регуляторных систем организма) - на $58 \%$.

Выраженность изменений находится в зоне значимости с данной доверительной вероятностью $\mathrm{p} \leq 0,01$.

Данные, полученные в ходе исследования показателей ВРС контрольной группы представлены ниже (таблица 2).

Пациенты контрольной группы, прошедшие комплексную реабилитацию на втором стационарном этапе медицинской реабилитации, не участвовавшие в БОСтренинге обнаружили следующие улучшения: АМо (цена адаптации) - на 1,5\%, ИВР (индекс вегетативного равновесия- на 12,3 \%, ИН (индекса напряжения)- на 11,1 \%.

При этом выраженность изменений по вышеперечисленным показателям находится в зоне незначимости $(p<0,05)$.

Таблица 1.

Сводные данные показателей ВРС в экспериментальной группе

\begin{tabular}{|c|c|c|c|c|}
\hline \multirow{2}{*}{ Показатели ВРС } & Исходные & Конечные & \multicolumn{2}{|c|}{ Сдвиги } \\
\cline { 3 - 5 } & & & абсол.вел. & 27,6 \\
\hline АМо, $\%$ & 82,1 & 59,5 & 1473,2 & 55,1 \\
\hline ИВР, у.е. & 2672,4 & 1199,2 & 1168,9 & 58 \\
\hline ИН, у.е. & 1992,9 & 824 & & \\
\hline
\end{tabular}

Таблица 2.

Сводные данные показателей ВРС в контрольной группе

\begin{tabular}{|c|c|c|c|c|}
\hline \multirow{2}{*}{ Показатели ВРС } & Исходные & Конечные & \multicolumn{2}{|c|}{ Сдвиги } \\
\cline { 3 - 5 } & & & абсол.вел. & 1,2 \\
\hline АМо, $\%$ & 80,7 & 82,5 & 306,2 & 1,5 \\
\hline ИВР, у.е. & 2482,4 & 2176,2 & 203,1 & 12,3 \\
\hline ИН, у.е. & 1828,3 & 1625,2 & 11,1 \\
\hline
\end{tabular}


Полученные результаты можно интерпретировать следующим образом. Вероятно, что обучение пациентов психофизиологическому расслаблению посредством БОС-тренинга способствует улучшению исследуемых показателей вариабельности ритма сердца: благоприятствует нормализации вегетативного баланса (соотношения влияния на сердечно-сосудистую систему симпатической и парасимпатической систем), степени напряжения механизмов регуляции сердечного ритма, увеличению ресурсов адаптации.

Результаты исследования расширяют теоретиче- ские представления о возможности применения БОСтехнологий для оптимизации процесса медицинской реабилитации пациентов, перенесших аортокоронарное шунтирование, и, таким образом, могут быть использованы специалистами помогающих профессий, причастных к реабилитации пациентов после аортокоронарного шунтирования, в частности специалистами мультидисциплинарных бригад, для помощи пациентам в освоении навыка психофизиологического расслабления, нормализации ВРС, что, в свою очередь, способствует общему успеху реабилитации.

\section{ЛИТЕРАТУРА}

1. Авцын А.П. Адаптация и дезадаптация с позиций патолога / А.П. Авцын // Клиническая медицина. - 1974. - Т. 52, №5. - С.3-15.

2. Агаларова, Л.С. Роль врача общей практики в формировании здорового образа жизни / Л.С. Агаларова // Здравоохранение Российской Федерации. 2006. - № 4. - C. 44-47.

3. Акчурин Р.С., Ширяев А.А. Актуальные проблемы коронарной хирургии. - М.: Гэотар Медицина, 2004 - С. 7-18.

4. Аладышев А.В., Субботин Е.А. Функциональное биоуправление с обратной связью - перспективная информационная технология в медицине. // Современные наукоемкие технологии. - 2005. - № 3. - С. 86-87.

5. Анализ вариабельности ритма сердца (возрастные аспекты) / 0.В. Коркушко [и др.]. - Киев, 2002. - 127 с.

6. Баевский, Р.М. Анализ вариабельности сердечного ритма: история и философия, теория и практика / Р.М. Баевский // Клиническая информатика и телемедицина. - 2004. - № 1. - С. 54-64.

7. Баклушина Е.К., Баклушин А.Е., Александрийская Н.Е., Белова В.В., Бурсикова Д.В. Исходный уровень медицинской активности пациентов на первом этапе кардио- и нейрореабилитации. // Вестник Ивановской медицинской академии. - 2014. - Т. 19. - № 2. - С. 5-9.

8. Бокерия Л.А., Коваленко О.А., Ирасханов А.К. и др. Сравни тельные отдаленные результаты полного артериальногокоронарного шунтирования и реваскуляризации внутренней грудной артерией и венами // Бюллетень научного центра сердечнососудистой хирургии им. А.Н. Бакулева РАМН. Сердечнососудистые заболевания. - 2012. - Т. 13, № 2. - С. 49-57.

9. Власова В.П. Возможности БОС-технологий в адаптивном физическом воспитании и реабилитации детей с ограниченными возможностями здоровья. // Теория и практика физической культуры. - 2016. - № 8. - С.32-34.

10. Диагностика и лечение нарушений регуляции сердечно-сосудистой системы : материалы XI науч.-практ. конф. (Москва, 25 марта 2009 г.) / Главный клинический госпиталь МВД России. - М., 2009. - 456 с.

11. Дубачев А.А. Оценка вариабельности сердечного ритма у пациентов, перенесших аортокоронарное шунтирование: дис. ... канд. мед. Наук. - Курск, 2012, - 127 с.

12. Ибатов, А.Д. Вариабельность ритма сердца при ортопробе и показатели центральной гемодинамики у больных ишемической болезнью сердца с сопутствующей артериальной гипертензией / А.Д. Ибатов // Российский кардиологический журнал. - 2004. - №1. - С. 76.

13. Иващенко А.С., Ежов В.В., Северин Н.А., Прокопенко Н.А. Эффективность медицинской реабилитации про ишемической болезни сердца в составе санаторно-курортного лечения. // Евразийский кардиологический журнал. - 2017. - №2. - С.28 -32.

14. Куватов В.А., Миронов В.А., Бавыкин М.В., Миронова Т.Ф. Вариабельность сердечного ритма у больных ишемической болезнью сердца при аортокоронарном шунтировании. // Вестник удмуртского университета. - 2012. -№2. - С.168-178.

15. Лекции по кардиологии / под ред. Л.А. Бокерия, Е.З. Голуховой : в 3 т. - М. : Изд-во НЦССХ им. А.Н. Бакулева РАМН, 2001. - Т. 2. - 288 с.

16. Миронова Т. Ф., Миронов В. А. Вариабельность сердечного ритма при ишемической болезни сердца. - 2 - е изд., испр. и доп. - Челябинск: Рекпол, 2008. - 173 С.

17. Михайлова Т.В. Психологические факторы в декомпенсации хронической сердечной недостаточности: дис. ... канд. психол. наук. - СПб., 2006. - 200 c.

18. Николаев Е.Л., Лазарева Е.Ю. Психотерапия и психологическая помощь больным с сердечно-сосудистыми заболеваниями. // Вестник психиатрии и психологии Чувашии. - 2015. - Т. 11. - № 1. - С.57-76.

19. Федотчев А.И. Современные нелекарственные методы регуляции сна у человека. // Физиология человека. - 2011. - Т. 37, № 1. - С. $126-135$.

20. Федотчев А.И., Бондарь А.Т., Матрусов С.Г. и др. Использование сигналов обратной связи от эндогенных ритмов пациента для нелекарственной коррекции функциональных расстройств // Успехи физиол. наук. - 2006. - Т. 37. № 4. - С. 82.

21. Шабалкин Б.В. Становление и развитие коронарной хирургии // Грудная и сердечно-сосудистая хирургия. - 2001. - № 2. - С. 4-7.

22. Шальнова С.А., Вихирева О.В. Оценка суммарного риска сердечно-сосудистых заболеваний. // Региональная фармакотерапия в кардиологии. - 2005. №3. - C. 54-56.

23. Эфрос Л.А., Самородская И.В. Факторы, оказывающие влияние на отдаленную выживаемость после коронарного шунтирования (обзор). // Сибирский медицинский журнал. - 2013. - Т. 28, № 2. - С.7-14.

24. Comparison of coronary bypass surgery with angioplasty in patients with multivessel disease: The Bypass Angioplasty Revascularization Investigation (BARI) Investigators // N. Engl. J. Med. - 1996 - Vol. 335, No. 4 - P. 217-225. 